Int. J. Electrochem. Sci., 15 (2020) $8808-8822$

\title{
Fabrication of Gold nanoparticles/Carbon Quantum Dots Nanocomposites for the Electrochemical Analysis of Ascorbic Acid, Dopamine and Uric Acid
}

\author{
Yuyun $\mathrm{Wei}^{1, \dagger}$, Zhifang $\mathrm{Xu}^{1, \dot{\dagger}}$, Di Zhang ${ }^{2, *}$, Yuxin Fang ${ }^{1, *}$ \\ ${ }^{1}$ Research Center of Experimental Acupuncture Science, College of Acumox and Tuina, Tianjin \\ University of Traditional Chinese Medicine, Tianjin 301617, PR China \\ ${ }^{2}$ College of Pharmaceutical Engineering of Traditional Chinese Medicine, Tianjin University of \\ Traditional Chinese Medicine, Tianjin 301617, PR China \\ *E-mail: 43987073@qq.com (D. Zhang), meng99_2006@126.com (Y.X. Fang) \\ †These authors contributed equally.
}

doi: $10.20964 / 2020.09 .82$

Received: 1 June 2020 / Accepted: 10 July 2020 / Published: 10 August 2020

A sensitive and straightforward sensor consisting of a glassy carbon electrode (GCE) containing carbon quantum dots (CQDs), and gold nanoparticles (AuNPs), was fabricated for simultaneous detection of ascorbic acid (AA), dopamine (DA) as well as uric acid (UA). Composite AuNPs/CQDs/GCE and its components were examined using high-resolution transmission and field emission scanning electron microscopies (HRTEM and FESEM, respectively), energy-dispersive and electrochemical impedance (spectroscopies EDS and EIS, respectively), as well as cyclic voltammetry (CV). The synergetic effect, of AuNPs and CQDs provided GCE with an outstanding electrocatalytic rate and excellent selectivity towards AA, DA, and UA oxidation in $0.1 \mathrm{M}$ PBS. The linear response ranges of the electrodes were 300-700 and 800-3500 $\mu \mathrm{M}$ for AA, 2-32 $\mu \mathrm{M}$ for DA, and 30-100 and 120-200 $\mu \mathrm{M}$ for UA. The peak potential separation values $\left(\triangle \mathrm{E}_{\mathrm{p}}\right)$ of AA-DA, DA-UA, and AA-UA pairs were equal to 150,130 , and $280 \mathrm{mV}$, respectively. The sensitivity of AuNPs/CQDs/GCE was 0.012 and $0.0057 \mu \mathrm{A} / \mu \mathrm{M}$ towards AA, $405.13 \mu \mathrm{A} / \mu \mathrm{M}$ towards DA, as well as 0.148 and $0.044 \mu \mathrm{A} / \mu \mathrm{M}$ towards UA. Our electrochemical sensor showed excellent stability, analysis reproducibility, and repeatability.

Keywords: Carbon quantum dots; Au nanoparticles; Ascorbic acid; Dopamine; Uric acid

\section{$\underline{\text { FULL TEXT }}$}

(C) 2020 The Authors. Published by ESG (www.electrochemsci.org). This article is an open access article distributed under the terms and conditions of the Creative Commons Attribution license (http://creativecommons.org/licenses/by/4.0/). 